\title{
The Effects of Losartan and Enalapril Therapies on the Levels of Nitric Oxide, Malondialdehyde, and Glutathione in Patients with Essential Hypertension
}

\author{
Gulzade DONMEZ, Ulver DERICI*, Deniz ERBAS, Turgay ARINSOY*, \\ Ayhan ONK ${ }^{\dagger}$, Sukru SINDEL ${ }^{*}$, and Enver HASANOGLU ${ }^{\ddagger}$ \\ Departments of Physiology, * Nephrology, ${ }^{\dagger}$ Neurosurgery, and ${ }^{\ddagger}$ Pediatric Nephrology, \\ Gazi University Faculty of Medicine, Ankara, 06510 Turkey
}

\begin{abstract}
Several recent studies have shown that essential hypertension is associated with increased oxidative stress, which may cause hypertension via enhanced oxidation and inactivation of nitric oxide. In this study, we investigated the malondialdehyde, nitric oxide, and glutathione levels in newly diagnosed essential hypertensive patients and whether or not there was any effect of antihypertensive treatment with angiotensin II type 1 receptor antagonist, losartan or angiotensin converting enzyme inhibitor, enalapril on plasma malondialdehyde, nitric oxide, and glutathione values. We selected 17 patients (F/M: 10/7, mean age: $46.12 \pm 9.2$ years) for enalapril therapy (10-20 mg/d) and 14 patients (F/M: $8 / 6$, mean age: $47.7 \pm 7.5$ years) for losartan therapy (50-100 mg/d), and compared them with 12 normotensive controls. At the be-
\end{abstract}

ginning of the study, both treated groups showed significantly higher plasma malondialdehyde and lower glutathione and nitric oxide in exhaled air compared to the control group. After 9 weeks of enalapril and losartan treatment, both systolic and diastolic pressure were significantly reduced. Both enalapril and losartan produced a significant decrease in plasma malondialdehyde and a significant increase in plasma glutathione levels and nitric oxide in exhaled air after 9 weeks. Initial values of plasma nitrate levels in patient groups were similar to the control group and increased significantly after the treatment period. In conclusion, both losartan and enalapril may be regulators between oxidant stress and the antioxidant system. [Japanese Journal of Physiology, 52, 435-440, 2002]

Key words: essential hypertension, antioxidant system, oxidant stress.

Oxidative stress is often used to imply a condition in which the cells are exposed to excessive levels of molecular oxygen or chemical derivatives of oxygen called reactive oxygen species (ROS). ROS is involved in the pathogenesis of many cardiovascular diseases, including hypercholesterolemia, atherosclerosis, hypertension, diabetes mellitus, and heart failure [1-3]. Excessive production of ROS has been implicated in processes in which they oxidize biological macromolecules such as DNA, protein, carbohydrate, and lipids [3]. In the vascular wall, increases in oxidant stress are thought to alter some important functions such as regulation of blood flow, inhibition of leukocyte adhesion, and control of cellular growth [2].

Essential hypertension is associated with impaired endothelium-dependent vasorelaxation and loss of endothelial production and/or bioavailability of nitric oxide (NO). In experimental hypertension in rats, it has been demonstrated that angiotensin II, some cytokines (like tumor necrosis factor- $\alpha$ ), and stretch increased the production of superoxide radicals by activating oxidases in vascular smooth muscle cells $[2,4]$. Excessive superoxide combines with NO to form the highly reactive oxidant peroxynitrite [1]. Lipid radicals and hydroxyl radicals may also react with NO. Therefore, NO bioactivity is reduced in the vascular

Received on June 12, 2002; accepted on September 2, 2002

Correspondence should be addressed to: Ulver Derici, Department of Nephrology, Gazi University Hospital, 06510 Besevler, Ankara, 06510 Turkey. Tel: +90-312-2141000 ext 5229, Fax: +90-312-2129006, E-mail: derici@med.gazi.edu.tr 
wall [3]. Moreover, when NO reacts with molecular oxygen, nitrogen dioxide $\left(\mathrm{NO}_{2}\right)$ is produced and this initiates lipid peroxidation. Lipid peroxidation has been found to produce unsaturated aldehydes, malondialdehyde (MDA), and other metabolites which are cytotoxic and mutagenic products [5]. These metabolites are capable of inactivating many cellular proteins by forming protein cross-linkages [5]. The levels of free radical scavengers such as vitamin E, glutathione (GSH), and superoxide dismutases (SOD) have also been reported to be depressed in hypertensive patients $[6,7]$. In recent years, different types of antioxidant interventions have been reported. Some of them included oestradiol therapy, vitamin $\mathrm{E}$ or $\mathrm{C}$ application, SOD analogues, nitric oxide synthase (NOS), and SOD gene transfer, beta blocker therapy such as carvedilol, nebivolol, and renin-angiotensin system (RAS) inhibition therapy [1]. Especially, angiotensinconverting enzyme (ACE) inhibitors have been shown to improve endothelium-dependent vasodilation in hypertensive rats and humans [1]. The studies about the effects of angiotensin II type 1 (AT1) receptor antagonists on oxidant status in hypertensive patients are insufficient. We aimed to determine the effects of an ACE inhibitor (enalapril) and AT1 receptor antagonist (losartan) on MDA levels, which is the last toxic product of lipid peroxydation, and on antioxidant capacity such as GSH as well as NO levels in patients with essential hypertension and make a comparison with normotensive controls.

\section{PATIENTS AND METHODS}

Patients. Thirty-one patients with grade 1, 2 or 3 essential hypertension according to Joint National Committee VI classification were included in our study. They were not treated with any antihypertensive medication prior to the study. The physical examinations, blood and urine laboratory analysis, abdominal ultrasounds, and standard electrocardiograms were conducted before antihypertensive therapy. Patients with essential hypertension were divided into two groups. Patients for each group were selected at random. The first group, consisting of 17 patients, was treated with ACE inhibitor (enalapril, $10-20 \mathrm{mg} / \mathrm{d}$ ), and the second group, consisting of 14 patients, was treated with AT1 receptor antagonist (losartan, $50-100 \mathrm{mg} / \mathrm{d}$ ) for 9 weeks. Both groups were on a salt-restricted diet. The control group consisted of 12 healthy normotensive subjects matched for age and sex and did not receive any treatment. There was no history of alcohol or tobacco use in both control and patient groups. All patients and healthy controls gave
Table 1. Some characteristics of the control group and patient groups.

\begin{tabular}{lccc}
\hline & $\begin{array}{c}\text { Enalapril } \\
(n=17)\end{array}$ & $\begin{array}{c}\text { Losartan } \\
(n=14)\end{array}$ & $\begin{array}{c}\text { Control } \\
(n=12)\end{array}$ \\
\hline Age (year) & $46.12 \pm 9.2$ & $47.7 \pm 7.5$ & $40.8 \pm 7.4$ \\
Female/male & $10 / 7$ & $8 / 6$ & $6 / 6$ \\
BMI $\left(\mathrm{kg} / \mathrm{m}^{2}\right)$ & $27.1 \pm 0.8$ & $25.27 \pm 2.8$ & $24.8 \pm 2$ \\
\hline
\end{tabular}

informed consent. Some characteristics of the control and patient groups before treatment are given in Table 1.

Patients with diabetes mellitus, chronic liver or renal disease, congestive heart failure, cerebrovascular or coronary artery disease, cardiomyopathy, or creatinine clearance higher than $140 \mathrm{ml} / \mathrm{min}$ and proteinuria higher than $150 \mathrm{mg} / 24 \mathrm{~h}$ were not included. The routine blood and urine laboratory analysis, arterial blood pressure measurements, levels of plasma nitrate, NO in exhaled air, plasma MDA, and GSH were determined at baseline and at the end of the 9th week of enalapril and losartan therapies. Blood samples were obtained in the morning after overnight fasting and the analysis of NO in exhaled air was performed simultaneously in both groups.

\section{Methods.}

Preparations of the plasma samples. Five milliliters of blood was drawn into a test tube with ethylenediaminetetra-acetate (EDTA) via vacutainer from the right antecubital fossa of each patient. The plasma samples were placed in Eppendorf tubes and stored at $-20^{\circ} \mathrm{C}$ for the analysis of nitrate, MDA, and glutathione.

The measurement of NO in exhaled air. The measurements of NO in the environmental air and in exhaled air were done using a Sievers 280 model NO analyzer.

The measurement of nitrate. A modification of the method described by Bramen and Hendrix was used [8]. The containers were washed using deionized water and then dryed. A mixture of $500 \mu 1$ plasma and $1,000 \mu \mathrm{l}$ ethanol at $0^{\circ} \mathrm{C}$ (for protein denaturation) in a microcentrifugation tube was vortexed for $30 \mathrm{~s}$ and then centrifuged at $4^{\circ} \mathrm{C}$ and $\sim 14,000 \mathrm{rpm}$ for $5 \mathrm{~min}$. A $10-\mu 1$ sample was taken from the supernatant and the nitrate level was measured using a Sievers 280 model NO analyzer.

The measurement of MDA. The method described by Kurtel et al. [9] was used. One milliliter of thiobarbituric acid/trichloracetic acid/hydrochloric acid was added to $500 \mu \mathrm{l}$ plasma in a microcentrifugation tube 
and then vortexed for $30 \mathrm{~s}$. The mixture was centrifuged at $10,000 \mathrm{rpm}$ for $5 \mathrm{~min}$ and the supernatant was placed into a glass tube. Ten microliters of butylated hydroxytoluene was added to this mixture and boiled for $15 \mathrm{~min}$. The sample was evaluated in comparison with distilled water at $532 \mathrm{~nm}$ in a spectrophotometer, and the MDA level was calculated using the following formula: Plasma $\mathrm{MDA}=$ adsorbance $\times$ $19.2 \mathrm{nmol} \mathrm{MDA} / \mathrm{ml}$ plasma.

The measurement of GSH. The method described by Kurtel was used [9]. Plasma $(500 \mu \mathrm{l}), 1 \mathrm{ml}$ hydrochloric acid/Na dodesil sulfate/EDTA $(\mathrm{pH}=8.2)$, and $50 \mu \mathrm{l}$ of $1 \mathrm{mM} 5$-aminosalysilate (for inhibition of glutathione oxidation) were placed in a microcentrifugation tube and centrifuged at $25^{\circ} \mathrm{C}$ and $12,000 \mathrm{rpm}$ for $5 \mathrm{~min}$. Ditionitrobenzoic acid $(0.3 \mathrm{mM})$ was added into the supernatant and the glass tube was kept at $37^{\circ} \mathrm{C}$ for $20 \mathrm{~min}$. The sample was read at $412 \mathrm{~nm}$ in a spectrophotometer, and the GSH level was calculated using the following formula: Plasma glutathione $=$ $3.18 \times$ adsorbance $/ 0.0136 \mathrm{nmol} / \mathrm{ml}$.

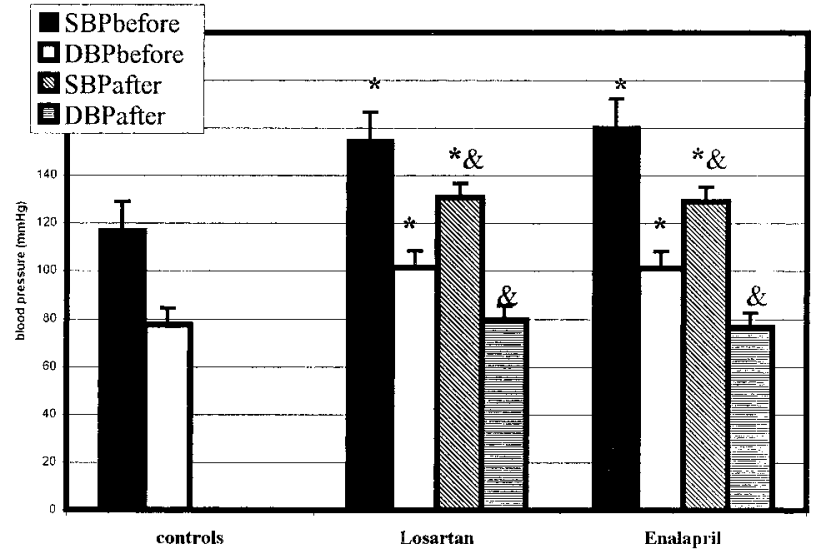

Fig. 1. Systolic (SBP) and diastolic blood pressure (DBP) levels in patient and control groups. After treatment, SBP and DBP decreased significantly (ANOVA $p>0.05$ for DBP). The mean SBP levels of two patient groups were still higher than the control group, but remained within normal limits $(<140 \mathrm{mmHg}) .{ }^{*} p<0.05$ vs. controls; \& $p<0.05$ vs. before treatment.
Statistical methods. Results are expressed as means \pm SD. To determine the significance between different groups, one-way analysis of variance was performed followed by the Tukey post hoc test. Paired Student's $t$-test was used to compare the differences from baseline within each group. A $p$ value $<0.05$ was considered to be significant.

\section{RESULTS}

Baseline mean systolic (SBP) and diastolic blood pressures (DBP) were 160.3 \pm 15.8 and 101.2 \pm 5.7 $\mathrm{mmHg}$ in the enalapril group, 154.6 \pm 10.4 and $101.4 \pm 8.4 \mathrm{mmHg}$ in the losartan group, and 117.1 \pm 6.8 and $77.5 \pm 4.5 \mathrm{mmHg}$ in the control group. After 9 weeks of antihypertensive therapy, SBP and DBP were $129.1 \pm 7.7$ and $76.5 \pm 5.5 \mathrm{mmHg}$, respectively, in the enalapril group and $130.7 \pm 4.7$ and $79.6 \pm 4.9 \mathrm{mmHg}$, respectively, in the losartan group. DBP levels in both treatment groups were similar to those of the control group $(p>0.05)$. SBP levels in both treatment groups were higher than those of the control group, but remained within normal limits (Fig. 1).

NO levels in exhaled air from essential hypertensive patients without treatment were significantly lower than those of the control group $(p<0.05)$, but it increased significantly following antihypertensive treatment in both treatment groups. However, NO levels in exhaled air from the two treatment groups were still significantly lower than the control. Before therapy, plasma nitrate levels were not different between groups $(p>0.05)$. However, after 9 weeks of treatment with ACE inhibitor and AT1 receptor antagonist, the mean plasma nitrate level of hypertensive patients increased significantly to $24.6 \pm 8.6 \mu \mathrm{M}$ in the enalapril group ( $p=0.03$ vs. control) and $22.5 \pm 10.5 \mu \mathrm{M}$ in the losartan group ( $p>0.05$ vs. control and enalapril group) (Table 2).

In essential hypertensive patients, the mean plasma MDA level, a product of lipid peroxidation, was found to be higher than that of the control group $(p=0.01)$.

Table 2. Results of the hypertensive patients and normotensive controls.

\begin{tabular}{|c|c|c|c|c|c|}
\hline & \multirow{2}{*}{ Control } & \multicolumn{2}{|c|}{ Losartan } & \multicolumn{2}{|c|}{ Enalapril } \\
\hline & & $\begin{array}{c}\text { Before } \\
\text { treatment }\end{array}$ & $\begin{array}{c}\text { After } \\
\text { treatment }\end{array}$ & $\begin{array}{c}\text { Before } \\
\text { treatment }\end{array}$ & $\begin{array}{c}\text { After } \\
\text { treatment }\end{array}$ \\
\hline NO in exhaled air (ppb) & $31.3 \pm 5.2$ & $12 \pm 7.2^{*}$ & $19.5 \pm 11.6^{\star, \dagger}$ & $13.3 \pm 5.5^{\star}$ & $20.8 \pm 10^{\star, \dagger}$ \\
\hline $\mathrm{Pl}$ nitrate $(\mu \mathrm{mol} / \mathrm{l})$ & $15.9 \pm 5.4$ & $14.5 \pm 5.5$ & $22.5 \pm 10.5^{\dagger}$ & $18.2 \pm 7.8$ & $24.6 \pm 8.6^{*, \dagger}$ \\
\hline MDA $(\mathrm{nmol} / \mathrm{ml})$ & $2.7 \pm 0.5$ & $3.8 \pm 1.3^{\star}$ & $2.8 \pm 1^{\dagger}$ & $4.3 \pm 1.6^{\star}$ & $2.39 \pm 0.6^{\dagger}$ \\
\hline $\mathrm{GSH}(\mathrm{nmol} / \mathrm{ml})$ & $220.1 \pm 79.2$ & $101.1 \pm 47.8^{\star}$ & $206.0 \pm 82.5^{\dagger}$ & $88.9 \pm 23.9^{\star}$ & $180.9 \pm 66.6^{\dagger}$ \\
\hline
\end{tabular}

${ }^{*} p<0.05$ vs. control; ${ }^{\dagger} p<0.01$ vs. before treatment. 
However, the mean plasma MDA level decreased from $4.3 \pm 1.6$ to $2.39 \pm 0.6 \mathrm{nmol} / \mathrm{ml}$ with ACE inhibitor therapy and from $3.8 \pm 1.3$ to $2.8 \pm 1 \mathrm{nmol} / \mathrm{ml}$ with AT1 receptor antagonist therapy. The mean level of MDA after treatment in both treatment groups was similar to that of the control group ( $p>0.05$ ). Plasma GSH levels, as a major component of the antioxidant system, were also measured before and after treatment. The hypertensive group had low mean plasma GSH level at baseline, but this increased significantly following antihypertensive therapy. After 9 weeks, mean plasma GSH levels in both treatment groups did not differ from that of the control group $(p>0.05)$. The increase in mean GSH level was more evident in the losartan group, but this increase was not statistically different from that of the enalapril group $(p=0.6)$ (Table 2).

\section{DISCUSSION}

Plasma MDA level, an index of lipid peroxidation, GSH, a component of the antioxidant system in essential hypertensive patients, and the effects of therapy with enalapril and losartan on these levels were examined in this study. NO in exhaled air and plasma nitrate levels were also examined in the same population as well as control subjects. The mean SBP and DBP decreased to within normal ranges with both ACE inhibitor and AT1 receptor antagonist therapy. Mean plasma MDA level was significantly higher and the GSH level was significantly lower in the essential hypertensive patients as compared to the control group before therapy, and plasma MDA decreased and GSH increased with both enalapril and losartan therapy. The increase in mean GSH level was more evident in the losartan group, but this increase was not statistically different from that in the enalapril-treated group. Plasma nitrate and NO in exhaled air also increased following both two treatment types.

In several recent studies, an increase in ROS has been demonstrated in patients with various hypertensive disorders [7, 10-14], in rats with cyclosporine-induced hypertension [15], in spontaneously hypertensive rats [16], in Dahl-sensitive rats [17], and in women with preeclampsia [18]. It has been suggested that oxidative stress may contribute to the generation and maintenance of hypertension via the inactivation of NO by ROS, the nonenzymatic generation of vasoconstrictive prostaglandine-like compounds called isoprostanes ( $\mathrm{F}_{2}$-isoprostane and $\mathrm{E}_{2}$-isoprostane) from arachidonic acid peroxidation and direct vasopressor action $[19,20]$. High blood pressure alters normal tissue oxygenation and leads to relative tissue hypoxia.
Hypoxia, itself, activates xanthine oxidase, which acts as a primary source of the $\mathrm{O}_{2}^{-\cdot}, \mathrm{H}_{2} \mathrm{O}_{2}{ }^{\circ}$, and $\mathrm{HO}^{-}$radicals as the end product. The last one may initiate the lipid peroxidation process and lead to an increase in MDA production [21]. Russo et al. demonstrated that essential hypertensive patients had higher MDA and GSH peroxidase activities and lower SOD activities, vitamin $\mathrm{A}$ and $\mathrm{E}$ levels, and $\mathrm{Cu}$ concentrations compared to the controls, and suggested that oxidative stress is important in the pathogenesis of essential hypertension or in the arterial damage related to essential hypertension [13]. In human and animal models, it has been believed that an imbalance between the production of reactive oxygen species and the antioxidant defence mechanisms may contribute to the pathogenesis of hypertension and its complications [11, 12, 22]. However it is unclear whether or not oxidative stress is the cause or the consequence of hypertension.

In this study, we found an increase in mean plasma GSH level, a decrease in mean plasma MDA level, and a significant increase in mean NO level, as shown in plasma and exhaled air, in hypertensive patients following the normalization of SBP and DBP with enalapril and losartan. This suggests that both enalapril and losartan may prevent oxidative stress in hypertensive patients by inhibiting lipid peroxidation. Even though we were unable to examine the other free radicals such as $\mathrm{O}_{2}^{-*}, \mathrm{OH}^{-}$, and $\mathrm{H}_{2} \mathrm{O}_{2}{ }^{-}$, we believe that antihypertensive therapy could also reduce them.

It has been reported that angiotensin II (Ang II) increases $\mathrm{O}_{2}{ }^{-*}$ in cultured vascular smooth muscle cells, human vascular endothelial cells (HVECs), and in the rat vascular ring mediated by AT1 receptors. In addition, it has been demonstrated that this effect could be eliminated by losartan [23-25]. The role of Ang II type 2 (AT2) receptors has not been known in free radical formation. Zhang had demonstrated that Ang II-induced $\mathrm{O}_{2}^{-\cdot}$ generation in HVECs is mediated by both AT1 and AT2 receptors [23]. However, in contrast to the AT1 receptor, the signal transduction cascade in response to Ang II-induced AT2 receptor possibly induces activation of the antioxidant system such a GSH activity [23]. After blockage of AT1 receptors by losartan-like drugs, the excess Ang II remains in the plasma and various tissues where some amount bounds to AT2 receptors. Recent data suggests that this receptor may have antiproliferative and antioxidant effects, and may contribute to the antiatherosclerotic effect of losartan [26]. In this study, we didn't examine the mechanisms of free radical formation after stimulation of both angiotensin receptor subtypes by Ang II. Further studies are necessary to explain the effects of AT2 receptor stimulation on oxida- 
tive stress and the antioxidant defence system. In our study, we couldn't find any significant difference between the effect of losartan and enalapril on plasma nitrate, NO in exhaled air, MDA and GSH levels. Considering the plasma oxidant and antioxidant systems in the study group, AT1 receptor antagonist does not seem to be more effective than ACE inhibitor. Our data is not sufficient to conclude that AT2 receptor stimulation secondary to AT1 blockage by various drugs may be beneficial for essential hypertensive patients.

Under pathologic conditions, stimulated $\mathrm{O}_{2}{ }^{-\cdot}$ production may contribute to the inhibition of prostacyclin formation, accelerated breakdown of $\mathrm{NO}$, a known potent vasodilator and inhibitor platelet aggregation, and increased oxidative modification of lowdensity lypoprotein (LDL) to oxidized LDL. Therefore, it may also be involved in atherosclerotic events [23]. ACE inhibitors and Ang II receptor antagonists have been found to attenuate atherosclerotic events by inhibiting $\mathrm{O}_{2}{ }^{-\cdot}$ production from vascular cells [23]. Therefore, they may be accepted as causative antiatherosclerotic agents since they act as a kind of "antioxidant" due to altering Ang II synthesis or blockading the Ang II receptor, thus causing a decrease of $\mathrm{O}_{2}{ }^{-}$. release in the circulation [23, 26]. Hayek et al. demonstrated that both fosinopril and losartan therapy inhibited LDL oxidation and attenuated atherosclerosis, independent of lowering blood pressure in apolipoprotein E-deficient mice. Direct inhibition of Ang II action in the arterial wall may be responsible for these results [26].

The physiologic response to increased shear stress and cyclic strain in hypertension is to upregulate NOS activity in endothelial cells. This activity is a homeostatic adaptation [27]. However, enhanced degradation of NO by increasing ROS along with reducing NO bioviability in the vascular wall have also been demonstraeted. In some studies, it has been shown that plasma NO levels increased with ACE inhibitor $[4,28,29]$ as well as calcium channel blocker therapy [30]. In our study, NO levels in the exhaled air of hypertensive patients rose after treatment, but it is not clear whether or not this increase was due to endogenous NO production. However, we suggest that the increase of plasma nitrate concentrations after treatment with these two different drugs may improve vascular endothelial function together with an increase in GSH and decrease in MDA levels.

In conclusion, we detected a high oxidant stress, low antioxidant and NO activities in patients with essential hypertension. Both enalapril and losartan therapies improved not only the blood pressure, but also the imbalance between the oxidant and antioxidant systems. Similarly, improved plasma NO activity may help to restore NO-related endothelial functions. We may speculate that the ACE inhibitors and AT1 receptor antagonists, which lead to an increase in NO production and scavenge free radicals, may help to protect patients from the severe complications of hypertension.

\section{REFERENCES}

1. Berry C, Brosnan MJ, Fennell J, Hamilton CA, and Dominiczak AF: Oxidative stress and vascular damage in hypertension. Curr Opin Nephrol Hypertens 10: 247255, 2001

2. Kojda G and Harrison D: Interactions between NO and reactive oxygen species: pathophysiological importance in atherosclerosis, hypertension, diabetes and heart failure. Cardiovasc Res 43: 562-571, 1999

3. Cai $\mathrm{H}$ and Harrison DG: Endothelial dysfunction in cardiovascular disease. Circ Res 87: 840-844, 2000

4. Taddei S, Virdis A, Ghiadoni L, Sudano I, and Salvetti A: Antihypertensive drugs and reversing of endothelial dysfunction in hypertension. Curr Hypertens Rep 2: 64-70, 2000

5. Dhalla NS, Temsah RM, and Netticadan T: Role of oxidative stress in cardiovascular diseases. J Hypertens 18: 655-673, 2000

6. Kumar KV and Das UN: Are free radicals involved in the pathobiology of human essential hypertension? Free Radic Res Commun 19: 59-66, 1993

7. Sagar S, Kallo IJ, Kaul N, Ganguly NK, and Sharma BK: Oxygen free radicals in essential hypertension. Moll Cell Biochem 111: 103-108, 1992

8. Bramen RS and Hendrix SA: Nanogram nitrite and nitrate determination in environmental and biological materials by vanadium (III) reduction with chemiluminescence detection. Anal Chem 61: 2715-2718, 1989

9. Kurtel H, Granger N, and Tso P: Vulnerability of intestinal interstitial fluid to oxidant stress. Am J Physiol 263: G573-G578, 1992

10. Vaziri ND, Oveisi F, and Ding Y: Role of increased oxygen free radical activity in the pathogenesis of uremic hypertension. Kidney Int 53: 1748-1754, 1998

11. El'chaninova SA, Galaktionova LP, Tolmacheva NV, and Varshavskii Bla: Activity of intracellular antioxidant enzymes in hypertensive patients. Ter Arkh 72: 51-53, 2000

12. Koska J, Syrova D, Blazicek P, Marko M, Grna JD, Kvetnansky R, and Vigas M: Malondialdehyde, lipofuscin and activity of antioxidant enzymes during physical exercise in patients with essential hypertension. J Hypertens 17: 529-535, 1999

13. Russo C, Olivieri O, Girelli D, Faccini G, Zenari ML, Lombardi S, and Corrocher R: Anti-oxidant status and lipid peroxidation in patients with essential hypertension. J Hypertens 16: 1267-1271, 1998

14. Sozmen B, Kazaz C, Taskiran D, Tuzun S, and Sozmen EY: Effect of $\mathrm{N}$-dicyclopropylmethyl-amino-2-oxazoline (S-3341) on antioxidant status and nitric oxide in hypertensive patients. Curr Med Res Opin 14: 89-96, 
1998

15. Navarro-Antolin J, Hernandez-Perera O, Lopez-Ongil S, Rodriguez-Puyol M, Rodriguez-Puyol D, and Lamas S: CsA and FK506 up-regulate eNOS expression: role of reactive oxygen species and AP-1. Kidney Int 68 (Suppl): S20-S24, 1998

16. Schnackenberg CG, Welch WJ, and Wilcox CS: Normalization of blood pressure and renal vascular resistance in SHR with a membrane-permeable superoxide dismutase mimetic: role of nitric oxide. Hypertension 32: 59-64, 1998

17. Swei A, Lacy F, DeLano FA, and Schmid-Schonbein GW: Oxidative stress in the Dahl hypertensive rat. Hypertension 30: 1628-1633, 1997

18. Roggensack AM, Zhang Y, and Davidge ST: Evidence for peroxynitrite formation in the vasculature of women with preeclampsia. Hypertension 33: 83-89, 1999

19. Vaziri ND, Wang XQ, Oveisi F, and Rad B: Induction of oxidative stress by glutathione depletion causes severe hypertension in normal rats. Hypertension 36: 142-146, 2000

20. Roberts LJ II and Marrow JD: The generation and actions of isoprostanes. Biochim Biophys Acta 1345: 121-135, 1997

21. Dijordjevic VB, Pavlovic D, Pejovic M, Cvetkovic T, Lecic N, and Deljanin-llic M: Changes of lipid peroxides and antioxidative factors levels in blood of patients treated with ACE inhibitors. Clin Nephrol 47: 243-247, 1997

22. Nicod L, Rodriguez S, Letang JM, Viollon-Abadie C, Jacqueson $A$, Berthelot $A$, and Richert L: Antioxidant status, lipid peroxidation, mixed function oxidase and UDP-glucuronyl transferase activities in livers from control and DOCA-salt hypertensive male Sprague Dawley rats. Mol Cell Biochem 203: 33-39, 2000

23. Zhang $H$, Schmeisser $A$, Garlichs CD, Plötze $K$, Damme U, Mügge A, and Daniel WG: Angiotensin IIinduced superoxide anion generation in human vascular endothelial cells: role of membrane-bound $\mathrm{NADH}-$ /
NADPH-oxidases. Cardiovasc Res 44: 215-222, 1999

24. Griendling KK, Minieri CA, Ollerenshaw JD, and Alexander RW: Angiotensin II stimulates NADH and $\mathrm{NADPH}$ oxidase activity in cultured vascular smooth muscle cells. Circ Res 74: 1141-1148, 1994

25. Rajagopalan S, Kurz S, Munzel T, Tarpey M, Freeman BA, Griendling KK, and Harrison DG: Angiotensin IImediated hypertension in the rat increases vascular superoxide production via membrane NADH/NADPH oxidase activation. Contribution to alterations of vasomotor tone. J Clin Invest 97: 1916-1923, 1996

26. Hayek T, Attias J, Coleman R, Brodsky S, Smith J, Breslow JL, and Keidar S: The angiotensin-converting enzyme inhibitor, fosinopril and the angiotensin II receptor antagonist, losartan, inhibit LDL oxidation and attenuate atherosclerosis independent of lowering blood pressure in apolipoprotein E deficient mice. Cardiovas Res 44: 579-587, 1999

27. Bataineh A and Raij L: Angiotensin II, nitric oxide, and end-organ damage in hypertension. Kidney Int 68 (Suppl): S14-S19, 1998

28. Higashi $Y$, Sasaki S, Nakagawa K, Ueda T, Yoshimizu A, Kurisu S, Matsuura H, Kajiyama G, and Oshima T: A comparison of angiotensin-converting enzyme inhibitors, calcium antagonists, beta-blockers and diuretic agents on reactive hyperemia in patients with essential hypertension:a multicenter study. J Am Coll Cardiol 35: 284-291, 2000

29. Kohno M, Yokokawa K, Minami M, Yasunari K, Maeda $\mathrm{K}$, Kano H, Hanehira T, and Yoshikawa J: Plasma levels of nitric oxide and related vasoactive factors following long term treatment with angiotensin-converting enzyme inhibitor in patients with essential hypertension. Metabolism 48: 1256-1259, 1999

30. Dijkhorst-Oei LT, Beutler JJ, Stroes ES, Koomans HA, and Rabelink TJ: Divergent effects of ACE-inhibition and calcium channel blockade on NO-activity in systemic and renal circulation in essential hypertension. Cardiovasc Res 40: 402-409, 1998 